mood distorting his experience and behaviour; of the serum lithium level and hence the potenand where effective medication is known it tial for renal damage is decreased. cannot responsibly be withheld.

Psychotherapeutic support is always needed by the child and his family but by itself leads to the danger that the child will merely adapt to his illness and circumstances, and only appear to improve. The aim of treatment must be to restore him fully to his previous personality, perhaps of many years ago.-ED, $B M \mathcal{H}$.

SIR,-There is one particular area I would like to comment on regarding your otherwise comprehensive leading article (27 January, p 214) on this topic-namely, side effects of lithium therapy in the young. Some special precautions are necessary because of the vulnerability of the age group under consideration. The narrow margin between the therapeutic and toxic levels of lithium in the serum is well known, and side effects such as abdominal pain, vomiting, tremors, and drowsiness when they occur in the young could be particularly distressing. Hence not only must the parent have easy access to the therapist when toxic effects appear, but the young person should be seen by the therapist at more frequent intervals than adults. The suppressant action of lithium on the thyroid has been established. Although pre-existing renal dysfunction is a contraindication of lithium therapy, whether lithium itself causes renal damage is not clear and is currently under investigation. It is also now known that lithium affects calcium metabolism. Hence it is clear that lithium therapy in the young should be carried out with extreme caution.

The Federal Drug Administration cautions against the use of lithium in children under 12 . Lithium thus should not be used in this group unless there are special indications. The special implications and precautions necessary regarding side effects of lithium therapy with young people have recently been described. ${ }^{1-3}$ For the past three years a double-blind controlled investigation sponsored by the Southeast Thames Regional Health Authority has been carried out in this hospital. ${ }^{4}$ More detailed accounts of this work are in preparation and I will be quite happy to provide details for anyone who is interested.

Proteinurea, although not an established side effect of lithium therapy in adults, has occurred with disturbing frequency in our group of children. Two other side effects which need to be emphasised are the occurrence of memory impairment and fine tremors of the hands which affect the handwriting. The implications of these two side effects for a child at school are obvious.

I would like to endorse one of the indications for lithium therapy in young people referred to in your leader-aggressive behaviour. However, I would qualify this by saying that this should be hyperaggressive behaviour occurring in an adolescent over 12 not amenable to other intense psychological methods of intervention (family group therapy, behaviour modification, etc). In these circumstances short-term lithium therapy for up to six months could be beneficial. ${ }^{2} 3$ Long-term lithium therapy in the young should be avoided. There is some evidence that the antiaggressive action of lithium probably requires a lower dose and lower serum concentration than those recommended-namely, 0.6-1.5 $\mathrm{mmol}(\mathrm{mEq}) / 1 .^{3}$ Lithium, when given to young people, should be given in a sustained release preparation-because then there is less peaking
Department of Child and Family Psychiatry, Eastbourne District General Hospital, Eastbourne, East Sussex

1 Lena, B, Excerpta Medica, International Congres Series, in press. Royal College of Psychiatrists, London, 1978 Aggression, Royal Society, London, 1978 (proceed-
ings to be published by Raven Press).

Lena, B, Surtees, S J, and Maggs, R, in Lithium in Medical Practice, p $79-83$ ed F N Johnson, and S Johnson, p 79 . Lancaster, Medical and Technical
Publishing Press, 1978.

\section{Is there a hyperkinetic syndrome?}

SIR,-Whatever the merits of the "hyperkinetic syndrome" one has to accept that hyperactive children present a real problem and one which is often referred to child psychiatrists for treatment. It may well be that hyperactivity, a most striking symptom is a child's common response to a number of separate clinical and aetiological entities.

In my practice I have found it useful to look at hyperactivity as a psychomoto manifestation akin to the psychomotor acceleration of adult hypomania. Dynamically, one can consider adult motor acceleration to be a manic defence against depression. Depression in children does not present itself in the adult pattern. For one thing, the motor control and the psychic developments are incomplete. Psychic awareness of depression by the child generally begins in adolescence. However, many of the other symptoms of adult depression are present in conjunction with the child's psychomotor acceleration. I have often found in the history a disturbance in the mother-child relationship dating back to the time of birth, the infant not seeming to respond satisfactorily to maternal care (depressed infant?) or maternal care being clumsy or otherwise unsatisfactory to the infant (maternal depression often present) The fact that children in the United States respond to psychic stimulants such as dexamphetamine and methylphenidate is, in my opinion, not a "paradoxical response" but rather the response which one would usually expect from depressed adults after intake of the very same psychic stimulants.

Haloperidol (plus orphenadrine) is probably the most effective drug in controlling the child's motor acceleration but it does no affect favourably the psychic depressive component in the syndrome. The administration of a tricyclic antidepressant by itself or together with the haloperidol appears to be much more effective and certainly a more rational treatment. Appropriate drug treatmen for the mother should also be considered. Family therapy and psychotherapy focusing on the mother-child relationship, both present and past, is an invaluable aid.

Ros ZiNNA

SIR,-The notion of the medical model for definining diagnosis expressed in your leading article of 24 February (p 506), is false. You state that the medical model is based on "bacterial infections with distinctive symptoms and signs, predictable course and outcome, and a relatively consistent response to treatmentand all backed up with positive cultures." To equate the medical model with somatic patho-
Lena, B, paper presented to quarterly meeting of the

Family Psychiatry Clinic, logy alone greatly limits the concept; the medical model embraces psychopathology as well as somatic pathology.

Had the correct model been employed in evaluating the authenticity of the "hyperkinetic syndrome" it would soon have become apparent that hyperkinesis is a symptom rather than a syndrome and in a particular patient represents somatic pathology or psychopathology, or an interaction of both; indeed the data given in your editorial point clearly in this direction.

Institute of Family Psychiatry,

J G Howells Institute of Family
Ipswich, Suffolk

\section{Labetalol and urinary catecholamines}

SIR,-We have already reported (24-31 December 1977, p 1673) that elevated levels of urinary catecholamines occur after the administration of labetalol. Further reports have been published in this journal which indicate that when radioenzymatic detection methods are used for the measurement of catecholamines, then normal levels are observed after labetalol administration by $\mathrm{Dr}$ C A Hamilton and others (16 September, p 800) and by Dr R Kolloch and others (27 January, p 268). This is in contrast with the finding that conspicuously elevated levels occur when fluorimetric method measurements are used, as reported by the same authors.

We have shown that no significant elevation of plasma noradrenaline or adrenaline occurs after acute intravenous administration of labetalol. ${ }^{1}$ Measurement of catecholamines was performed using the high-performance liquid chromatography (HPLC) method of Riggin and Kissinger ${ }^{2}$ and our results are similar to those already reported. ${ }^{2}$ Further extensive studies in our laboratories have shown that when fluorimetric methods of catecholamine measurement are used elevated levels do occur after the use of labetalol. Thus we can confirm that labetalol in biological fluids interferes with fluorimetric methods of analysis but that no such interference occurs when HPLC methods are used.

It is therefore important not to attribute clinical significance to elevated plasma or urinary catecholamine levels if these measurements have been made using fluorimetric methods. Furthermore, we recommend that urinary 4-hydroxy-3-methoxymandelic acid (HMMA) and not catecholamine or metanephrine excretion should be measured when screening for phaeochromocytoma in patients who are being treated with labetalol.

\section{A RICHARDS \\ D M HARRIS L E MARTIN}

Glaxo-Allenburys Research (Ware) Ltd,

Ware, Herts

${ }^{1}$ Richards, D A, Prichard, B N C, and Hernandez, R,
British fournal of Clinical Pharmacology, 1979, in
press.
2 Riggin, M, and Kissinger, T, Annals of Chemistry,
1977, 49, 2109.

No more textbooks on primary care?

SIR,-I agree with Dr Ian Tait (27 January, p 256) in praying for no more textbooks on general practice. A book which covered everything the GP ought to know would prove a daunting load for a strong man with a 